\title{
Analysis of PHILOS Plating for Displaced Proximal Humeral Fractures
}

\author{
Pandurangaiah Srinivas* \\ Assistant Professor, Department of Orthopaedics, Sri Devaraj Urs Medical College, India
}

Received: December 15, 2017; Published: January 04, 2018

*Corresponding author: Pandurangaiah Srinivas, Assistant Professor, Department of Orthopaedics, Sri Devaraj Urs Medical College, Tamaka, Kolar, Karnataka, India, No.1919, South End 'C' Cross road, 28th Main road, 9th Block, Jayanagar, Bangalore, Karnataka state, India. Pin: 560069, Tel: 0091-8861245971; Email ID: srinivas_pandurangaiah@rediffmail.com

\section{Introduction}

Fractures of proximal humerus are still unsolved fractures. Fixation techniques are plenty and none is ideal for all cases [1]. These fractures can be displaced, unstable and may have disruption of the blood supply. The treatment of these fractures is therefore a therapeutic challenge [2]. The majority of patients with this fracture are elderly, hence osteoporotic or brittle. Treatment options include transosseous suture fixation, tension band wiring, percutaneous wire, screw fixation, standard plate, precontoured locking plate, PHILOS plate and hemireplacementarthroplasty. The Proximal humeral internal locking system (PHILOS) plate fixation provides greater angular stability than do conventional implants. It works as a locked internal fixator and provides better anchorage of screws in osteoporotic bone $[3,4]$ with good functional outcomes $[5,6]$. In proximal humerus fractures, PHILOS plate offers a good functional outcome in context to the early joint mobilisation and rigid fixation of the fracture [7]. Considering these advantages and the scarcity of data on the efficacy and the functional outcome following PHILOS plate for displaced proximal humerus fractures, the present study was planned.

\section{Materials and Methods}

This study was conducted October 2015 to October 2017 inlcuding the follow-up period of six months. A total of 30 cases who sustained proximal humerus fractures were enrolled in the study.Inclusion criteria:

a) Patients with 2-, 3- or 4-part proximal humeral fracture.

b) Patients aged greater than 18 years.

Exclusion criteria:

a) Type III-C compound fractures.

b) Patients not fit for surgery due to any pre-existing morbidity.

Patients fulfilling the selection criteria were informed about the nature of the study. The consent for surgery and anaesthesia were taken.History was taken and clinical examination was done. Patients were subjected to routine preop investigations. X-ray - Shoulder AP,Lateral and trans-axillary(optional) view were taken. CT scan was done in selected cases. The surgery was done through deltopectoral approach, the fracture site was exposed. The anatomical relationship between humeral head and greater tuberosity was reduced and fixed temporarily with $\mathrm{K}$ wires.

When acceptable reduction was obtained, the PHILOS plate was placed at least $1 \mathrm{~cm}$ distal to the upper end of the greater tuberosity and fixed to the humeral shaft. The head fragments were secured with Kirschner wires. Four to six locking screws were then inserted. Fluoroscopic images were taken to confirm satisfactory fracture reduction, plate positioning and proper length of screws in the humeral head. Depending upon the pain, pendulum exercises were begun as soon as possible. At sixth to eighth week-full range of movements with active exercises started. Follow-up of patients was done at six weeks, three months and six months following the surgery.Patients were evaluated based on the following parameters at the time of discharge and all the follow ups:
a. Range of motion of the Shoulder.
b. Complications.
c. Clinical union.
d. Radiological union.

The final assessment using DASH [8] score for outcome was interpreted as : Excellent - 0 to 55 points, Good - 56 to 70 points, Fair -71 to 85 points, Poor- 86 to 100 points.Statistical analysis was performed.

\section{Results}

A total of 30 patients sustaining proximal humerus fractures were studied. There were 16 males (53.3\%). Majority were $>50$ yrs (56.66\%). In this study, $56 \%$ of the patients presented with 2-part fracture, $37 \%$ with 3-part fracture and $7 \%$ with 4 -part fracture of the proximal humerus according to Neer's classification. In the present study all the patients (100\%) had clinical and radiological 
union at minimum follow-up of 6 months. Pain was reported by $10 \%$ of the patients while complications noted were melanin (6.6\%) and stiffness (13.3\%). The final range of motion of abduction was 115.6 + - 16.7 degrees, flexion of $110+/-12.86$ degrees, external rotation of $57.3+/-8.2$ degrees, internal rotation of $60.6+/-12.8$ degrees. In the present study most of the patients had good outcome $(47 \%)$ followed by fair (26\%), excellent (20\%) and poor outcome $(7 \%)$ (Figures 1-4).

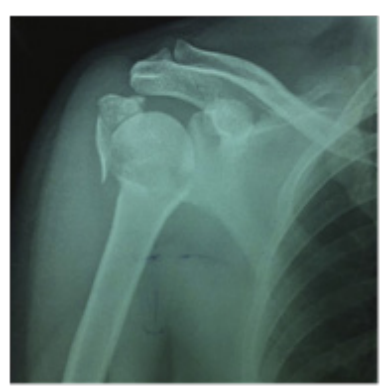

Figure 1: Preopxray.

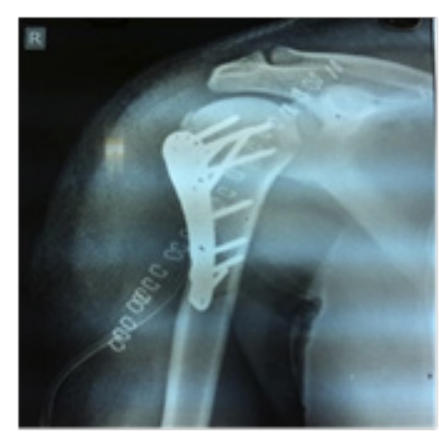

Figure 2: Immediate post op xray.

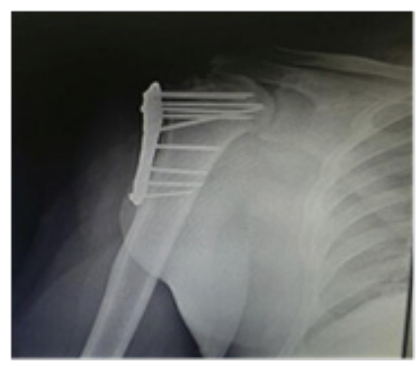

Figure 3: At 6 wks, union in progress.

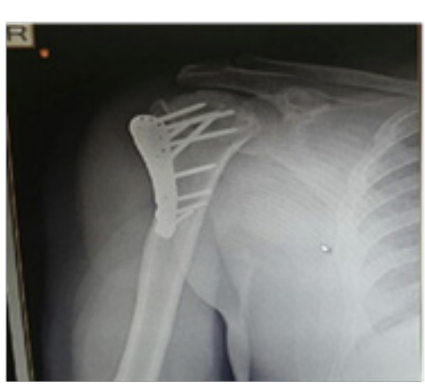

Figure 4: At 6 months, United.

\section{Discussion}

The benefits of PHILOS plate are that it gives enhanced purchase in osteopenic bone, there is no loss of reduction orvarus/valgus angulations, the locking screws into the plate provides angular and axial stability of the construct. Positioning the plate too high can also lead to incorrect placement of the divergent screws in the humeral head. Care should be taken to avoid penetration of the head and subsequent chondrolysis with proximal interlocking screws [9]. In a study Koukakis A et al. [10], the plate design provides stable fixation with a good functional outcome and eliminates most hardware problems such as failure and impingement syndrome. In 2009 MA Fazal et al. [11] concluded PHILO Splate fixation provided stable fixation, minimal metal work problem and enabled early range of motion exercises to achieve acceptable functional results. Egol KA et al. [12] showed $92 \%$ of his cases united at 3 months after surgery. The major complication reported in this study was screw penetration, suggesting that exceptional vigilance must be taken in estimating the appropriate number and length of screws used to prevent particular penetration. In 2009 Brunner F et al. [13] Primary screw perforation was the most frequent problem (14\%) followed by secondary screw perforation (8\%) and a vascular necrosis $(8 \%)$. Proximal humerus fractures, remain a challenging problem for the surgeon because the complication rate for these fractures still remains high. The internal locked system (PHILOS) plate is a new device used for proximal humerus fracture fixation is designed to decrease the high complication rate. In the present study complications observed were melanin (6.6\%) and stiffness (13.3\%).

\section{Conclusion}

PHILOS plate provides a high degree of angular and axial stability. The divergent and convergent orientation of the locking screws engaging in the humeral head prevent pull out and failure of fixation. Early physiotherapy and good rehabilitation programme is vital to get a good functional outcome. In conclusion, the PHILOS plate is an ideal construct and a stable implant to use for fractures of the proximal humerus in Neer's 2-part, 3-part, and 4-part and osteoporotic fractures of the proximal humerus in elderly patients

\section{References}

1. Gerald RW, Kirk L, Wong (2000) Two-part and three part fractures-Management of proximal and distal humours fracture. Orthop Clin North Am 31(1): 1-21.

2. Lous U, Bigiliani, Charles Rockwood, Frederick A (1990) Fractures of proximal humerus. Chapter 9 The shoulder. In Rockwood CA, Matsen. Philadelphia: WB Saunders 1: 278-334.

3. Siddaram N Patil, PandurangaiahSrinivas (2017) A prospective study of 30 cases of PHILOS plating for displaced proximal humeral fractures. IJOS 3(3): 86-91.

4. Helmy N, Hintermann B (2006) New trends in the treatment of proximal humours fractures. Clin Orthop Relat Res 442: 100-8.

5. Koukakis A, Apostolou CD, Taneja T, Korres DS, Amini A (2006) Fixation of proximal humerus fractures using the PHILOS plate: early experience. Clin Orthop Relat Res 442: 115-20.

6. Bjorkenheim JM, Pajarinen J, Savolainen V (2004) Internal fixation of proximal humeral fractures with a locking compression plate: a ret- 
rospective evaluation of 72 patients followed for a minimum of 1 year. Acta Orthop Scand 75(6): 741-745.

7. Kiliç B, Uysal M, Cinar BM, Ozkoç G, Demirörs H, et al. (2008) Early results of treatment of proximal humerus fractures with the PHILOS locking plate. Acta Orthop Traumatol Turc 42(3):149-153.

8. Hudak PL, Amadio PC, Bombardier C (1996) Development of an upper extremity outcome measure: the DASH (disabilities of the arm, shoulder and hand) [corrected]. The Upper Extremity Collaborative Group (UECG). Am J Ind Med 29(6): 602-608.

9. Thyagarajan DS, Haridas SJ, Jones D, Dent C, Evans R, et al. (2009) Functional outcome following proximal humeral interlocking systemplating for displaced proximal humeral fractures. Int J Shoulder Surg; 3(3) 57-62.
10. Koukakis A, Apostolou CD, Taneja T, Korres DS, Amini A (2006) Fixation of proximal humerus fractures using the PHILOS plate: early experience. Clin Orthop Relat Res 442: 115-120.

11. Fazal MA, Haddad FS (2009) PHILOS plate fixation for displaced proximal humeral fractures. J Orth Surg 17(1): 15-18.

12. Egol KA, Ong CC, Walsh M, Jazrawi LM, Tejwani NC, Zuckerman JD (2008) Early complication of proximal humerus fractures treated with locked plates. Jorthop trauma 22(3):159-164.

13. Brunner F, Sommer C, Bahrs C, Heuwinkel R, Hafner C, et al. (2009) Open Reduction and Internal Fixation of Proximal Humerus Fractures Using a Proximal Humeral Locked Plate: A Prospective Multicenter Analysis. J Orthop Trauma 23(3): 163-172.

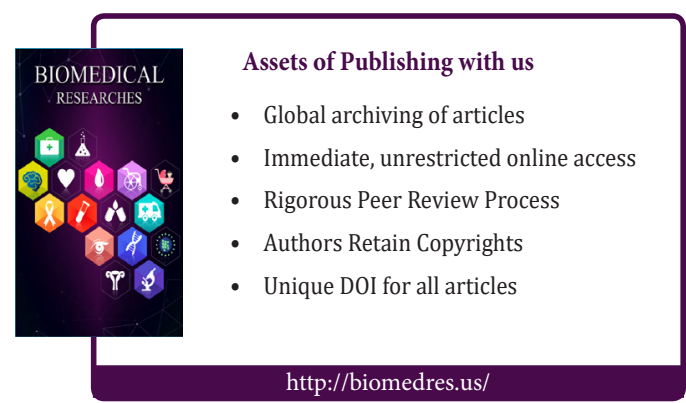

